\title{
Obras de arte, pontos de encontro, rastros de redes
}

\author{
Gabriel Menotti Gonring
}

Resumo: Evocando conceitos de Bourriaud (2006, 2007), Salles $(2006,2010)$ e Latour $(2005,2008)$, este artigo busca promover um enfoque relacional sobre o trabalho artístico. De acordo com essa abordagem, a obra não estaria contida em um objeto ou processo singular, nem dependeria unicamente do gesto criador do artista, mas existiria sempre em desenvolvimento, distribuída por uma rede-de-atores que inclui outras pessoas, objetos e processos. Procurarei destacar esse modo de existência chamando atenção para a maneira como a Fonte (1917), de Marcel Duchamp, estabelece um projeto expositivo. Presumindo as várias negociações (criativas e institucionais) por trás dessa obra, interessa-me demonstrar como as práticas curatoriais podem desempenhar uma função preponderante na topografia das redes de criação, uma vez que criam as condições de publicidade que tornam o trabalho artístico apreensível.

Palavras-chave: redes, mídia; processos de criação; obras de arte; curadoria.

Abstract: Works of art, meeting points, traces of networks - Drawing from the work of Nicolas Bourriaud (2006, 2007), Cecília Salles (2006, 2010) and Bruno Latour (2005, 2008), this paper seeks to promote a relational approach about artistic work. According to this approach, a work is not embodied in a single object or process, nor does it depend solely on the artist's creative gesture, but instead develops continuously within a network of actors that includes other people, objects and processes. In this paper, I attempt to highlight this mode of existence by outlining how Marcel Duchamp's sculpture Fountain (1917) establishes its own exposition agenda. By assuming the manifold negotiations (creative and institutional) behind this author's work of art, I seek to demonstrate how curatorial practices can play a predominant role in the topography of creative networks, since they establish the conditions of publicity that render works of art apprehensible.

Keywords: networks; media; creative processes; artworks; curatorship.

Nos anos 1990, o curador francês Nicolas Bourriaud observou a emergência de uma produção artística que parecia ao mesmo tempo reagir a e se apropriar da crescente estandardização dos laços sociais (BOURRIAUD, 2006, p. 7), negando a teleologia 
modernista em um afã de "modelar universos possíveis" (ibid., p. 11). Exemplos dessa tendência seriam o trabalho do argentino Rirkrit Tiravanija, que usa o espaço expositivo para preparar refeições e compartilhá-las com o público, bem como o projeto No Ghost Just A Shell (1999), em que Pierre Hughye e Philippe Parreno convidaram outros artistas para realizarem animações com um personagem de mangá do qual tinham adquirido o copyright.

Bourriaud reuniu algumas dessas obras na exposição Traffic, realizada no Centre D'Arts Plastiques Contemporains - CAPC, museu de arte contemporânea de Bordeaux, na França, em 1996. Foi no catálogo desse evento que ele, pela primeira vez, daria nome à tendência que tanto Ihe instigava: estética relacional. Em linhas gerais, esse termo se refere a práticas artísticas que produzem não apenas meros artefatos, mas sim "relações entre as pessoas e o mundo" (ibid., p. 51). Nelas, Bourriaud via a consolidação de um gênero criativo cujo horizonte seria o próprio contexto social das interações humanas.

Cética quanto às pretensões políticas por trás dessas alegações, Bishop viria a contestar a proposta de Bourriaud, ressaltando que diversas obras de arte relacional poderiam muito bem ser qualificadas como uma simples forma de instalação "que insiste no uso ao invés da contemplação" (BISHOP, 2004, p. 55). Segundo Bishop, apesar de sua "retórica de democracia e participação", grande parte dos trabalhos reunidos sob essa rubrica suprime os antagonismos necessários para a constituição de uma real esfera pública, sendo por vezes conivente com o programa conservador das instituições de arte, de suas empresas patrocinadoras e dos aparelhos estatais (ibid., p. 60).

Mesmo levando em consideração essas críticas, há alguns aspectos, levantados por Bourriaud, que parecem extremamente relevantes para o entendimento do modo como a obra de arte se constitui, particularmente no que se refere ao papel das práticas curatoriais nesse processo. Esses aspectos nos permitem vislumbrar mais nitidamente as dimensões política, técnica e socioeconômica da negociação entre a produção e a apresentação da obra.

Neste artigo, partirei desses aspectos para construir uma abordagem crítica suplementar à de Bourriaud. Em outras palavras, ao invés de focar na compreensão de um gênero de arte determinado relacional, apontarei para uma compreensão relacional do fazer artístico como um todo, em que a obra apareça como instância (ou meio de expressão) de uma rede de processos contínuos, desempenhados por diversos agentes. Entre esses processos, serão destacadas principalmente as práticas curatoriais, atuando em complementariedade ao trabalho do artista, e a própria situação material em que a obra subsiste e se dá à mostra. Assim, pretendo demonstrar diferentes aspectos do conjunto de elementos envolvidos no fazer artístico, bem como sugerir a sua complexidade. Essa perspectiva se beneficiará das noções de redes de criação (SALLES, 2006) e ator-rede (LATOUR, 2005), e será exemplificada por meio de um relato do trabalho de Marcel Duchamp. 


\section{Por uma compreensão midiática da obra de arte}

Primeiramente, é interessante ressaltar a atenção dedicada por Bourriaud ao papel do desenvolvimento de tecnologias midiáticas no estabelecimento do que ele denomina estética relacional. Entre os casos que menciona estão as condições sociais de produção, possibilitadas pelo computador e pela câmera fotográfica (BOURRIAUD, 2006, p. 87); a maleabilidade da imagem do vídeo (ibid., p. 93); e a popularização da internet (ibid., p. 102). Além disso, ele sinaliza uma sincronia entre o surgimento do readymade e a invenção do cinema (ibid., p. 141), sugerindo a complementariedade entre a história da arte e a dos sistemas de comunicação.

Bourriaud parece se inspirar não apenas pelas transformações internas do fazer artístico, mas também pela emergência de novas mídias, cujo funcionamento se baseia nas redes informáticas. É revelador que seus interesses posteriormente se voltariam para as práticas de pós-produção, comumente associadas a tecnologias digitais. Para ele, no entanto, essas práticas não estariam necessariamente atreladas ao emprego de computadores. Elas configurariam uma reação mais ampla à "multiplicação da oferta cultural" e à "inclusão no mundo da arte de formas até então ignoradas ou depreciadas" (Id., 2007, p.7).

O artista "pós-produtor" seria aquele dedicado à "tarefa de selecionar objetos culturais e inseri-los dentro de contextos definidos" (ibid., p. 8). Seu trabalho estaria baseado na programação de formas a partir de "objetos que já estejam circulando no mercado cultural, quer dizer, já informados por outros" (ibid., p. 7). Bourriaud vê nessa atividade uma superação da "distinção tradicional entre produção e consumo, criação e cópia, readymade e obra original" (ibid.). Para o autor, os expoentes máximos dessa prática seriam "semionautas" como o DJ e o "websurfer", cujas modalidades de criação se caracterizam pela "invenção de itinerários através da cultura" (ibid., p. 14). Embora ele não deixe explícito, não há nada que nos impeça de aplicar essa classificação também ao curador, obtendo assim uma forma legítima de entender a criatividade envolvida no seu papel.

Ao aproximar o trabalho do artista das práticas curatoriais, o regime de pós-produção parece apresentar um desdobramento natural da inserção desse trabalho na lógica de representação e circularidade própria das mídias. Bourriaud já vinha estabelecendo bases para uma tal compreensão do fazer artístico ao caracterizar a obra em exposição como um meio de contato com o seu processo de manufatura (BOURRIAUD, 2006, p. 49). Aqui, ele faz coro com Parreno, para quem o artefato não seria a conclusão do trabalho do artista (em outras palavras, uma mensagem que o artista quer transmitir), mas sim um dos vários "acontecimentos" desse trabalho (ibid., p. 65). Nesse sentido, a obra seria algo que mostra o fazer artístico, sem, no entanto, abreviá-lo ou constituir a sua causa final.

Bourriaud mobiliza essa perspectiva midiática de modo a ressaltar a dimensão intersubjetiva da arte, baseada "na copresença dos que observam e da obra" (ibid., p. 69). Na sua leitura, o papel do público ganha preponderância na medida em que é 
por meio das "interações humanas" que a forma artística adquire uma "existência real" (ibid., p. 22-23). Nesse sentido, o aliado de Bourriaud é Duchamp, que já havia declarado, em 1954, que "'aquele que observa' é o criador da obra, [que] ingressa nos arcanos da criação pelo viés do 'coeficiente de arte' que é 'a diferença entre o que (o artista) havia previsto realizar e o que efetivamente realizou'” (ibid., p. 125).

Doravante, a obra parece simplesmente sinalizar o encontro do público com uma forma artística que a transborda. O seu status como meio de expressão do fazer artístico não viria simplesmente dela própria, mas principalmente das situações de exposição em que essa intersubjetividade pode se realizar. Aí, o espaço expositivo aparece como um "campo de comércio de representações" (ibid., p. 16) ou um "domínio de intercâmbio" que escapa ao ritmo da vida cotidiana (ibid., p. 17). Podemos supor que, ao organizar esse estado de exceção, as práticas curatoriais desempenhariam um papel fundamental na existência da obra de arte. De modo a considerar essa hipótese em seus diversos aspectos, faz-se necessário trazer à tona a multiplicidade de processos que estariam implícitos em qualquer obra de arte, ainda que de maneira indireta.

\section{Multiplicidade de processos}

Uma forma de apreender a complexidade por trás de um trabalho de arte é passar a enxergá-lo não como um elemento estático, mas como algo em movimento - um sistema em constante interação com o seu ambiente (SALLES, 2006, p. 32). Segundo Salles, essa mudança de paradigma seria necessária "para se discutir arte em geral e aquela produzida nas últimas décadas de modo especial" (ibid., p. 16).

Apontando para a relevância dos "aspectos comunicativos" do fazer artístico (ibid., p. 32), os estudos de Salles podem nos auxiliar a compreender a sua heterogeneidade. De maneira ainda mais explícita do que Bourriaud, a autora destaca a obra de arte como um congelamento momentâneo de um processo contínuo de criação marcado pela troca de informações com o seu entorno.

Na definição de Salles, o movimento criador não se resumiria à coleção de procedimentos técnicos necessários para a produção de uma determinada obra. Ele operaria simultaneamente em diversas dimensões socioculturais e poéticas, constituindo de igual maneira "ação transformadora, movimento tradutório, processo de conhecimento, construção de verdades artísticas e percurso de experimentação" (ibid., p. 15). Não bastasse essa abundância de identidades, o processo criativo também possuiria contornos fundamentalmente indeterminados, sendo impossível precisar o seu começo ou término.

Outrossim, as características, enumeradas por Salles, vão todas de encontro aos mitos românticos do gesto definitivo, da inspiração platônica e da obra autossuficiente, criada ex nihilo. Ela aponta para "simultaneidade de ações, ausência de hierarquia, não linearidade e intenso estabelecimento de nexos" (ibid., p. 17). Diante dessa aparente desordem, que modelo poderia expressar satisfatoriamente o fazer artístico e possibilitar a sua análise? 
Para Salles, esse modelo seria a rede, um "novo paradigma ligado a um pensamento das relações" que ela toma emprestado do filósofo Pierre Musso ( apud ibid., p. 23). Em Musso, a rede aparece como uma estrutura formada por elementos que se interconectam de maneira instável, e cuja dinâmica de variações é intrínseca ao conjunto. De maneira imediata, tal imagem de rede ressalta a necessária interação entre as diversas decisões do artista (ibid., p. 27), bem como a continuidade de todos os elementos envolvidos no movimento criador, que podem ser tomados como "picos ou nós [...] ligados entre si" (ibid., p. 24).

Por meio do conceito de rede, ganhamos outra compreensão dos múltiplos resultados - ou rastros - aparentemente secundários do fazer artístico. Esse paradigma destaca todas as versões intermediárias que são fundamentais no processo de criação: os elementos cuja importância acabam, por vezes, sendo ofuscados pela obra "final", como anotações, planos, projetos, modelos, rascunhos e maquetes.

Desse modo, o fazer artístico aparece como essencialmente plural e multimídia, perpassando diversas linguagens (ibid., p. 95). Salles cita, por exemplo, o uso de diagramas e cartografias imaginárias pelo romancista Ignácio de Loyola Brandão (ibid., p. 99), e de textos reflexivos pelo artista visual Daniel Senise (ibid., p. 103).

Entretanto, ainda mais relevante é a maneira pela qual a noção de rede justifica a existência da obra como "inacabada e móvel" (ibid., p. 13) ao substituir as expectativas teleológicas sobre o processo criativo por

[uma] visão evolutiva do pensamento [do artista] que enfatiza as relações entre elementos já existentes. Sob esse ponto de vista, qualquer momento do processo é simultaneamente gerado e gerador (Colapietro, 2003), e a regressão e a progressão são infinitas. Foge-se, assim, da busca pela origem da obra e relativiza-se a noção de conclusão. (ibid., p. 26; grifos nossos)

Isso significa que o movimento criador passa a se dar em um nível principalmente inferencial (ibid., p. 152), que imprime a todo o fazer artístico um caráter de "programação de formas" similar àquele que Bourriaud havia identificado nas práticas de pós-produção.

Levando em conta esse horizonte de "regressão e progressão infinitas", é possível dizer que uma rede de criação não possui limites predeterminados - ou, nas palavras de Salles, ela "define seu próprio processo de expansão" (ibid., p. 33). Em última instância, tal processo apontaria não para a concretização de uma obra, mas para a "exibição de tendências" ou para a "satisfação de um projeto poético" (ibid., p. 157).

Esses desdobramentos derradeiros do movimento criador poderiam ser entendidos nos termos colocados por Kosuth em seu influente ensaio Art After Philosophy (1969). Kosuth diz que, depois de Duchamp, a arte estaria livre de morfologias específicas, de modo que qualquer trabalho artístico poderia constituir uma completa "definição da arte" (KOSUTH, 1996, p. 844). Todo processo de criação seria, assim, uma resposta legítima para a pergunta "o que é arte?", capaz de reprogramar os parâmetros do próprio sistema em que está inserido. 


\section{O papel do artista na rede}

Em face dessa abertura radical do processo criativo e do alcance quase irrestrito da sua influência transformadora, como podemos reexaminar a obra em exposição? Ou, colocando de outra forma: o que faria dessa obra uma expressão privilegiada do fazer artístico, ao invés de um rastro secundário como tantos outros?

A princípio, a determinação da obra parece estar plenamente condicionada a uma decisão do artista. Num exercício de livre arbítrio, o sujeito opta por interromper o processo criativo para dar-Ihe uma configuração definitiva, nem que seja na tentativa de se tornar senhor dos seus próprios limites. Nesse sentido, Salles recupera as palavras do escritor Thomas Carlyle: "Publicamos para não passar a vida corrigindo" (SALLES, 2006, p. 21).

Essa soberania do indivíduo sobre a concretização da obra é formulada de maneira ainda mais explícita por Duchamp, que resume o fazer artístico a um ato de seleção voluntária. Segundo ele, uma "escolha" pessoal é tudo o que bastaria para destacar um artigo qualquer da vida cotidiana e produzir "novo pensamento" a seu respeito (DUCHAMP, 1917).

Mas não sejamos tão apressados em atribuir ao artista o controle total sobre as redes de criação. Uma análise mais detalhada coloca a autonomia dessa figura em xeque. De fato, de acordo com a perspectiva radicalmente relacional que pretendemos adotar, o artista aparece como um resultado tão parcial da rede quanto a "sua" produção: ele se torna artista na medida em que o movimento criador se concretiza em obra. Assim, podemos perceber que outras coisas estão em movimento, além da matéria-prima do trabalho e da vontade do indivíduo.

Isso fica bastante claro na rocambolesca história da Fonte (1917), o readymade quintessencial. Com esse trabalho, Duchamp teria elevado o mero procedimento de eleger um objeto ao status de gesto criador. Mais tarde, Kosuth destacaria a revolução que a empreitada de Duchamp causou para o fazer artístico, transformando a identidade da obra de arte "de uma questão de morfologia para uma questão de função" (KOSUTH, 1996).

Contudo, ironicamente, a obra-prima que teria demonstrado ao mundo que o mero poder de escolha do artista seria capaz de colocar qualquer "artigo ordinário" em exposição e elevá-lo ao status de arte nunca foi exposta em primeiro lugar. O historiador William Camfield diz que o caso da Fonte é difícil de ser reconstituído com precisão devido à falta de registros oficiais (CAMFIELD, 1989, p. 71). Até onde se pode ter certeza, eis o que ocorreu: escondido sob o pseudônimo de Richard Mutt, Duchamp havia enviado um urinol de porcelana para a primeira exposição da American Society of Independent Artists, de Nova York. Esse evento possuía um caráter largamente inclusivo, e se propunha a colocar todos os trabalhos inscritos à mostra independentemente de seu "mérito artístico".

Não obstante, o conselho da associação julgou por bem recusar a participação da Fonte na exposição, por considerar a escultura excepcionalmente "imoral e vulgar" e um caso de "plágio", estando aquém da categoria de arte (CAMFIELS, 1989, p. 70-71). 
Essa decisão foi recebida com protestos por uma minoria da cena artística local, a começar pelo próprio Duchamp, que até então fazia parte do conselho do evento e por conta disso decidiu abandoná-lo (ibid., p. 68).

O debate sobre o caso se estendeu por algumas semanas na imprensa especializada, culminando em uma carta anônima publicada na segunda edição do periódico dadaísta The Blind Man, de maio de 1917. Essa carta, comumente atribuída a Duchamp, permanece como o principal registro de todo imbróglio (ibid., p. 68). O texto possui teor de manifesto, e vinha acompanhado de uma foto de página inteira da Fonte, trabalho até então inédito. Foi dessa forma, como a documentação de uma obra que nunca havia sido exposta, que o readymade se fez público pela primeira vez.

Logo, apesar das declarações de Duchamp, o que a história da Fonte demonstra é que o artista não foi capaz, com a sua mera decisão, de destacar um artigo qualquer do cotidiano e transformá-lo em arte. Inicialmente, ele contava com a conivência curatorial do comitê diretor da American Society of Independent Artists. Quando essa cumplicidade falhou, Duchamp se viu obrigado a assumir outros papéis e desempenhar uma série de ações suplementares, num esforço retórico para trazer a sua "obra" à tona e produzir um "novo pensamento" sobre o urinol.

Esse esforço foi tão inegavelmente bem-sucedido que acabou por produzir um novo pensamento sobre arte em geral, suprimindo as disputas iniciais sobre o readymade da consideração imediata do público. Mais do que isso, o trabalho de Duchamp se tornou uma espécie de jurisprudência à que qualquer um pode legitimamente recorrer (e muitos inadvertidamente o fazem) na intenção de concretizar uma obra de arte.

Podemos questionar se, a partir de então, a vontade do indivíduo sobre o fazer artístico passaria a ser soberana - ou se, pelo contrário, tornar-se-ia ainda menos suficiente, para sempre à sombra da tradição inaugurada pela Fonte. Em todo caso, as controvérsias por trás da obra nos chamam a atenção para o papel de diversos outros (elementos, personagens e instituições) em sua rede de criação.

É de se presumir que, da mesma forma que atuam a favor da vontade do artista, esses outros podem atuar contra ela. E, bem como impedem a concretização de uma obra, também podem impô-la ou trabalhar em prol da sua manutenção. Haja vista o caso do pintor pós-impressionista Pierre Bonnard, mencionado por Salles, que supostamente "entrava escondido nos museus, com pincéis e tintas, e nos momentos em que os guardas não estavam olhando, retocava os próprios quadros" (SALLES, 2010, p. 17). Não fosse a vigília desses funcionários, haveria uma força a menos para assegurar a aparente conclusão das pinturas e impedi-las de se dissolver no eterno movimento criador do artista.

Esses exemplos nos mostram algumas formas pelas quais o fazer artístico interage com o ambiente, dependendo de trocas de informação que não terminam nem mesmo na situação de exposição. Particularmente, eles chamam a atenção para as dinâmicas 
de distinção e cuidado envolvidas na concretização da obra. De forma a analisar mais detalhadamente essas atividades, comumente atribuídas ao curador, faz-se necessário expandir o arsenal teórico proporcionado por Bourriaud e Salles.

\section{Multiplicidade de atores}

De um lado, Bourriaud postula que o trabalho de arte existe de maneira essencialmente intersubjetiva; de outro, Salles afirma que o movimento criador se constitui por uma diversidade de processos que se entrelaçam. Nessa penúltima sessão, buscarei unir essas duas perspectivas de modo a avançar nossa compreensão relacional sobre o fazer artístico, despersonalizando-o. Essa fusão se dará através do trabalho do antropólogo Bruno Latour, que também nos permitirá considerações mais pungentes sobre as várias disputas que resultam e se expressam na obra.

Latour é um dos pais da teoria do ator-rede (actor-network theory, ou ANT) - que, a despeito do nome, é menos de uma teoria do que de uma abordagem de pesquisa. Essa disciplina nasceu a partir das tentativas "lamentavelmente fracassadas" de se fazer considerações sociológicas a respeito da própria ciência (LATOUR, 2005, p. 101). Ao se verem incapazes de relacionar de maneira relevante elementos tão diversos quanto os micróbios, experimentos em laboratório, bolsas de pesquisa e fatos científicos, Latour e seus colegas foram levados a abandonar a sociologia do "social" - entendido como uma substância ou domínio específico da realidade que dá conta de determinados fenômenos (ibid., p 4). Em seu lugar, surgiu a ANT.

Nesse sentido, a teoria do ator-rede pode ser considerada como uma sociologia das associações (ou uma "associologia"), plenamente relativista (ibid., p. 12) e que se mantém em contato direto com a metafísica e com a filosofia (ibid., p. 15). Seu patrono é Gabriel Tarde, pioneiro do século XIX, cujo trabalho teria sido ofuscado pelo projeto de "engenharia social" de Émile Durkheim (ibid., p. 13). O principal interesse dessa disciplina seria retraçar as conexões entre coisas que não são "sociais" por si próprias (ibid., p. 5).

Um dos primeiros preceitos da ANT é que nenhuma ação é realizada de maneira individual, sob pleno controle da consciência. Cada ação deve ser encarada "como um nó, uma amarra, e um conglomerado de várias coleções de agências surpreendentes" (ibid., p. 44). Nesse sentido, toda ação é coletiva, sendo impossível precisar não apenas seu início e seu fim (como no caso do processo criativo), como também o seu ator.

O hífen na expressão "ator-rede" implica justamente que os atores "representam a maior fonte de incerteza sobre a origem da ação" (ibid., p. 46). Eles seriam não a sua causa, mas sim os seus "alvos móveis" (ibid.). No caso, podemos recordar que o esforço de Duchamp para a concretização da Fonte não foi solitário, nem sequer partiu dele isoladamente. Tudo o que ele fez estava atrelado a um determinado estado de coisas, ao qual reagia ou com o qual negociava. Quem primeiro criou uma oportunidade 
para a obra foi a American Society of Independent Artists. De modo a realizar o trabalho, o artista ora conspirou, ora entrou em conflito com outros elementos da cena nova-iorquina. Paradoxalmente, o ator que parecia estar por trás de todo esse furdunço, o suposto autor da obra, era também o de existência mais incerta: "Richard Mutt".

Seria então a teoria do ator-rede outra maneira de afirmar a coletividade essencial de toda atividade humana? Algo semelhante é sugerido por Salles, que aponta para o fato de o sujeito ser "distinguível, mas não separável de outros, pois sua identidade é constituída pelas relações com os outros" (SALLES, 2010, p. 225). De maneira mais precisa, Bourriaud elege o binômio artista/curador como "o primeiro grau de relações humanas suscetíveis de determinar uma produção artística" (BOURRIAUD, 2006, p. 28). Diante dessas propostas, o que teria Latour a acrescentar?

A principal contribuição que a ANT pode dar à análise da obra de arte deriva do postulado que uma ação não se limita ao que é realizado de maneira significativa por seres humanos (LATOUR, 2005, p. 71). Se considerarmos que um conjunto de atores é "tudo aquilo que faz diferença num determinado estado de coisas", independentemente de sua intencionalidade (ibid.), somos levados a deduzir que objetos também são atores - e atores muito especiais.

Representando "entidades que não dormem" e "associações que não se desfazem", são os objetos que garantem a expansão e durabilidade de forças que de outra maneira se dissipariam (ibid., p. 70). Doravante, eles seriam os principais responsáveis por cristalizar processos e promover a inércia das redes de criação. Na anedota sobre Bonnard, por exemplo, é mister perceber que poderia haver outros elementos que, embora inauditos, oferecem ainda mais resistência à contínua intervenção do pintor do que os guardas do museu, como vitrinas protetoras e alarmes.

Aqui, talvez pudéssemos traçar uma conexão com a estética relacional de Bourriaud, quando ela estabelece que "atitudes se convertem em formas" que, por sua vez, induzem "modelos de relações sociais" (BOURRIAUD, op. cit., p. 70). A diferença fundamental é que Bourriaud parece estar preocupado apenas com as dinâmicas que se dão por meio da obra - certamente um dos principais objetos a concretizar o valor e sentido de determinado movimento criador, mas não o único. A perspectiva da ANT dirige nossa atenção para os outros, vários atores "que vivem nas margens do social fazendo a maior parte do trabalho, mas que nunca são representados como tais" (LATOUR, op. cit, p. 73): matéria-prima, ferramentas, rascunhos, ar condicionado, etiquetas, paredes, catálogos, panfletos, jornais, reproduções, etc.

Essa inspiração conduz a teoria do ator-rede na direção de um "segundo empirismo", que assume que tudo aquilo que tomamos por realidade resulta da "mobilização de diversas entidades cujo agrupamento (assemblage) poderia [eventualmente] falhar" (LATOUR, 2005, p.91). Mesmo verdades científicas precisam ser fabricadas em laboratório, por meio de experimentos artificiais (ibid., p. 90). De igual maneira, toda explicação 
(e inferência) envolveria "iniciativas muito práticas de construção-de-mundo que consistem em conectar entidades com outras entidades" (ibid., p. 103).

Nesse sentido, cada entidade poderia ser vista como uma coisa, ou "o tópico disputado de uma assembleia virtual" (ibid., p. 119). Longe de evidenciar a diversidade de "interpretações subjetivas" sobre uma "realidade objetiva", essa perspectiva busca derrubar essa separação por completo. Não é porque uma coisa estaria sujeita a disputas de valor e sentido que ela seria menos real. Ao mesmo tempo, não é porque uma coisa seja real que ela seria também incontestável (ibid., p. 111). São as coisas que, por elas próprias, "se deixam implantar de múltiplas maneiras" (ibid., p. 116).

Latour leva essa leitura às últimas consequências ao colocar a própria originalidade da obra como um efeito da negociação econômica de sua presença (LATOUR e LOWE, 2010). O antropólogo defende que todo trabalho de arte possui uma carreira, subsistindo por meio de reproduções, qualquer que seja o material utilizado. Mesmo para uma pintura, a "existência precede a essência" (ibid.): de modo a permanecer a mesma, no mesmo lugar, ela precisa constantemente se re-produzir. Cada versão da obra constitui um segmento mais ou menos fértil nessa trajetória de vida, podendo se desdobrar em outros ou, por outro lado, abreviar a sua circulação.

Nesse sentido, Latour considera que possa existir mais "aura" em um fac-símile do mural Nozze di Cana, reinstalado no seu sítio original, do que na pintura feita pelas mãos de Paolo Veronese e de seus assistentes, atualmente exposta no Louvre. No caso da cópia, a inesperada "fertilidade" vem da correspondência entre a composição interna da imagem e o contexto de exposição - algo que se perde ao transportá-la para o museu francês.

Na Fonte, encontramos um exemplo muito didático dessa existência vetorial das coisas, que embaraça ideias e objetos, conteúdos e contextos. Por trás da aparente simplicidade da obra está o agrupamento entre o urinol (que efetivamente se deixa "implantar como arte") e a situação de exposição.

Como vimos, essa não é uma conexão puramente abstrata ou, como as palavras de Duchamp nos querem levar a crer, uma mera "escolha" (DUCHAMP, 1917). Trata-se de uma articulação de elementos materiais e retóricos à qual a obra (e a própria possibilidade do readymade) está condicionada. Uma articulação que, por fim, vai se realizar de maneira indireta, na carta anônima publicada na revista The Blind Man.

Latour propõe que a "objetividade" proporcionada pela ANT seria especialmente conveniente para a análise de "situações em que proliferam inovações, em que as fronteiras entre grupos são incertas, [e] quando a variedade de entidades a serem levadas em consideração flutua" (LATOUR, op. cit., p. 11). Com os exemplos acima, espero ter demonstrado que essa disciplina também oferece um vocabulário rico para a compreensão da complexidade do fazer artístico, que nos permite escancarar os processos de criação e considerar os diversos atores neles envolvidos. 


\section{A obra como rede}

Concluirei esse artigo detalhando o conceito de rede empregado por Latour, e demonstrando como ele pode ser empregado em complementaridade ao de Salles na caracterização da obra como um meio de expressão do movimento criador.

Para a ANT, a rede não é um tipo de infraestrutura, mas uma perspectiva analítica sobre as associações que produzem um determinado estado de coisas - "uma ferramenta que auxilia a descrever alguma coisa, não o que está sendo descrito" (LATOUR, 2005, p. 131). De certa forma, é uma ideia que se aproxima da noção de dispositivo foucaultiana, por designar "aquilo em que, ou através do que, se realiza uma atividade de governança destituída de qualquer fundação no ser" (AGAMBEN, 2009, p. 7). Logo, a rede não é uma coisa que é, mas sim uma racionalização econômica do que pode vir a ser. Não sem gracejo, Latour sugere que a expressão mais adequada seria "work-net", abrangendo todo o trabalho que se desenvolve para compor uma net-work (LATOUR, op. cit., p. 132).

Essa perspectiva produziria distinções entre as entidades que representam um papel de intermediários (canais) e aquelas que atuam como mediadores (tradutores): as primeiras constituindo tudo o que "transporta sentido ou força sem transformá-los" (ibid., p. 39), enquanto que as outras "transformam, traduzem, distorcem, e modificam o sentido ou os elementos que supostamente carregam" (ibid., p. 39). Com essa separação, podemos acrescentar uma dimensão crítica à nossa compreensão midiática sobre o fazer artístico.

Ao invés de se mostrar como uma simples intermediária da vontade do artista (ou quiçá da interpretação do público), a obra em exposição aparece como o denominador comum entre vários mediadores. A relevância concreta de cada ator envolvido em sua constituição viria à tona, independentemente da forma como esses elementos estariam figurados na própria obra ou seriam explicados pelo artista. Isso nos permitirá ressaltar, por exemplo, a centralidade da carta publicada em The Blind Man para a invenção do readymade.

Simultaneamente, o objeto de arte poderia ser considerado como uma disputada prestação de contas (uma account) de associações que tendem ao infinito, articulando vários elementos e forças em conjunto. Nesse sentido, somos motivados a levar a sério a tirada de Duchamp de que "todas as pinturas são readymades porque seriam a mera combinação de produtos de consumo industrial, os tubos de tinta" (STALLABRASS, 1999, p. 163). Esse aspecto fica ainda mais evidente em obras que tomam a forma de projetos expositivos, um gênero que foi explorado pelo próprio Duchamp nas boîte-en-valises (1942-1954), série de maletas contendo reproduções bi e tridimensionais das obras do artista em miniatura (STORRIE, 2006, p. 54).

Dessa forma, o horizonte proporcionado pela teoria do ator-rede evidencia a obra à mostra também como uma espécie de "museu portátil", que contém e se constitui por outras; um território em que o artista reúne suas inspirações e as apresenta 
publicamente. Aqui, novamente, encontramos ressonâncias entre o fazer artístico e o desenho de uma exposição. De acordo com essa perspectiva, o artefato não seria uma simples representação da vontade do artista, nem sequer uma expressão direta de seu processo de criação, mas sim uma coisa disputada, em que diversas agências confluem e se deixam vislumbrar. Esse renovado entendimento poderia nos permitir delinear com maior precisão os entrelaçamentos das práticas curatoriais com a obra, trazendo à tona o papel do curador na existência do trabalho de arte.

Gabriel Menotti é critico, curador e professor na UFES; é doutor em Media and Communications por Goldsmiths (Universidade de Londres) e doutor em Comunicação e Semiótica pela PUC-SP. Apresentou trabalhos em eventos como o 160 ISEA, a 29a Bienal de São Paulo e o Festival Transmediale. É autor do livro Através da Sala Escura Espaços de Exibição Cinematográfica e VJing.

gabriel.menotti@gmail.com

\section{Referências}

AGAMBEN, G. What is an apparatus?. In: . "What is an apparatus?" and other essays. Tradução de David Kishik e Stefan Pedatella. Stanford: Stanford University, 2009, p. 01-24.

BISHOP, C. Antagonism and relational aesthetics. October. Cambridge, n. 110, 2004.

BOURRIAUD, N. Estética relacional. Tradução de Cecília Beceyro e Sérgio Delgado. Buenos Aires: Adriana Hidalgo Editora, 2006.

. Postproducción. Tradução de Sílvio Mattoni. Buenos Aires: Adriana Hidalgo Editora, 2007.

CAMFIELD, W. Marcel Duchamp's fountain: its history and aesthetic in the context of 1917. In: KUENZLU, R; NAUMANN, F. Marcel Duchamp: Artist of the century. Cambridge: MIT, 1989, p. 64-94.

DUCHAMP, M. The Richard Mutt case. The blind man, n. 2, maio 1917.

KOSUTH, J. Art after philosophy. In: STILES, K.; SELZ, P. Theories and documents of contemporary art: a sourcebook of artists' writings. Los Angeles: University of California, 1996, p. 841-846.

LATOUR, B. Reassembling the social: an introduction to actor-network-theory. Oxford: Oxford University, 2005

.A cautious Prometheus? A few steps toward a philosophy of design (with special attention to Peter Sloterdijk). In: NETWORKS OF DESIGN - PROCEEDINGS OF THE 2008 ANNUAL INTERNATIONAL CONFERENCE OF THE DESIGN HISTORY SOCIETY. 2008, Falmouth. Anais. Florida, Universal Publishers, 2009. p. 2-10.

; LOWE, A. The migration of the aura or how to explore the original through its fac similes. In: BARTSCHERER, T. Switching codes. Chicago: University of Chicago, 2010. 
SALLES, C. Redes da criação: construção da obra de arte. 2. ed. São Paulo: Editora Horizonte, 2006. Arquivos de criação: arte e curadoria. São Paulo: Editora Horizonte, 2010.

STALLABRASS, J. High art lite: british art in the 1990s. Reino Unido: Verso, 1999.

STORRIE, C. The Delirious Museum: a journey from the Louvre to Las Vegas. Nova York: Tauris e Co, 2006.

Artigo recebido em abril e aprovado em agosto de 2013. 